\title{
PREPARATION AND CHARACTERIZATION OF LOW MOLECULAR WEIGHT CHITOSAN WITH DIFFERENT DEGREES OF DEACETYLATION BY THE ACID HYDROLYSIS METHOD
}

\author{
NAWZAT D. AL-JBOUR ${ }^{\mathrm{a}, \mathrm{b}}$, M. D. H. BEG ${ }^{\mathrm{a}}$, JOLIUS GIMBUNa, A. K. M. MOSHIUL ALAMc \\ aCenter of Excellence for Advanced Research in Fluid Flow (CARIFF), Faculty of Chemical and Natural Resources Engineering, Universiti \\ Malaysia Pahang, Gambang 26300, Kuantan, Malaysia, bFaculty of Pharmacy, Middle East University, Amman, Jordan, cInstitute of \\ Radiation and Polymer Technology, Bangladesh Atomic Energy Commission, Dhaka, Bangladesh \\ Email: dhbeg@yahoo.com
}

Received: 27 Jan 2019, Revised and Accepted: 02 Jan 2021

\begin{abstract}
Objective: The objective of this research is to prepare Low Molecular Weight Chitosan (LMWC) by the acid hydrolysis method, using dilute hydrochloric acid (2M). LMWC has superior properties compared to the High Molecular Weight Chitosan (HMWC), especially in terms of water solubility, antibacterial and antifungal properties. These could open new potential applications for LMWC in sectors such as the cosmetics, food, and
\end{abstract} pharmaceutical industries.

Methods: In this work, the acid hydrolysis method was used to produce LMWC with different molecular weights starting from $500 \mathrm{kDa}$ and $93 \%$ degree of deacetylations (DDA). The molecular weights of the produced grades were determined by applying Mark-Houwink equation while the $\%$ DDA was determined and verified by the use of the 1 st derivative UV method and ${ }^{1} \mathrm{HNMR}$ method, respectively. The depolymerization reactions were carried out with different time intervals to produce totally deacetylated LMWC of $30 \mathrm{kDa}, 15 \mathrm{kDa}$, and $7.5 \mathrm{kDa}$. The LMWC was characterized by FTIR, XRD, and DSC to evaluate the functionality, microstructure and thermal properties.

Results: The FTIR spectra revealed that there is no significant difference in the main skeletal structure of the LMWC and HMWC. On the other hand, the XRD and DSC results showed that the LMWC of different molecular weights and degrees of deacetylation are of semi-crystalline structure, similar to the HMWC

Conclusion: The obtained results showed that the used acid hydrolysis procedure can produce LMWC grades of desired specifications, yields, and quality which are suitable for use in different applications.

Keywords: Acid hydrolysis, Acetylation, Chitosan Oligomers, Degree of deacetylation

(c) 2021 The Authors. Published by Innovare Academic Sciences Pvt Ltd. This is an open access article under the CC BY license (https://creativecommons.org/licenses/by/4.0/) DOI: https://dx.doi.org/10.22159/ijap.2021v13i2.32229. Journal homepage: https://innovareacademics.in/journals/index.php/ijap

\section{INTRODUCTION}

Chitosan is a biodegradable polymer obtained from the alkaline deacetylation of chitin. Both chitin and chitosan are linear copolymer which consists glucosamine and $\mathrm{N}$-acetyl glucosamine repeating units, linked by $\beta(1,4)$ glycosidic bonds as shown in fig. 1 . In the structure of chitosan glucosamine constitutes more than $50 \%$ of the repeating units. The degree of deacetylation of chitosan is in the range of 50$100 \%$ [1] and chitosan exhibits several unique properties, such as biocompatibility, biodegradability, biological activity and low-toxicity $[2,3]$. The characteristics of chitosan in solutions depend on its degree of deacetylation (DDA), distribution of acetyl groups, chain length, molecular weight distribution, and solubility [4]. Notably, the salient features of chitosan may be exploited in wide applications, especially in fields such as biomedical [5, 6], drug delivery systems [7], food [8], textile [9], and wastewater treatment [9]. Particularly, chitosan has been investigated for various potential applications in the pharmaceutical industry [10-12], especially in designing and developing different drug delivery systems. For example, high molecular weight chitosan (HMWC) polymers are used either alone, or with other hydrophilic polymers, as matrices for both immediate and controlled release drug formulations [13]. On the other hand, the free amino groups attached to glucosamine monomers complexes with different anionic drugs, and could be utilized in the design of different drug delivery systems [14].

The main challenge to the applications of chitosan is its limited solubility in water and other aqueous solutions. Notably, the low solubility of chitosan limits its interactions with different ionic drugs [15], as well as its use in the liquid protein delivery dosage forms [16]. Therefore, in order to overcome the limitation of the low solubility of chitosan, a lot of approaches have been explored to increase the solubility of chitosan $[10,14,17,18]$.

On the other hand, the wide application of chitosan can be sustained by using low molecular weight chitosan (LMWC). The LMWC is a generation of biopolymers produced through various chemical and/or physical treatment of high molecular weight chitosan (HMWC). The low molecular weight of these grades and their improved aqueous solubility have attracted wide research interest compared to the highly hydrophobic chitin and the sparingly soluble and pH-dependent high molecular weight chitosan. Therefore, these low molecular weight biopolymers have important applications in diverse fields such as bio-fertilizers in agriculture, waste treatment, as well as in critical and special applications in drug and gene delivery [19]. Biologically, LMWC has been reported to possess beneficial properties [20], which include decreasing blood cholesterol and blood pressure, protective effect against infections, arthritis control and antitumor properties [21-26]. For example, Nacetylchito-oligosaccharides and oligochitosans could inhibit the growth of fungi and phytopathogens and elicit defense mechanisms in plants [27-29]. In addition, they exhibit good lipid capability [30], and desirable antibacterial and anti-inflammatory properties [31].

Traditionally, LWCS have been successfully prepared starting with the HMWC using various physical, chemical and enzymatic depolymerization methods. Physical methods utilize ultrasound or microwave energies for hydrolyzing chitosan [32,33], whereas chemical methods typically employ strong liquid acids like hydrochloric acid, phosphoric acid, either independently or in combination [34, 35]. On the other hand, the enzymatic techniques majorly take advantage of specific enzymes like chitosanase and nonspecific enzymes like pepsin, papain etc., with varying success reported [36, 37].

In another vein, the acid hydrolysis method makes use of acids such as hydrochloric acid [15], nitrous acid [16], phosphoric acid, and hydrogen fluoride to depolymerize the HMWC [34]. For industrial applications, acid depolymerization using hydrochloric acid is preferred [38], as this method is usually simple, easy [10], and produces reasonably predictable mixtures of LMWC [18]. Nevertheless, the use of concentrated hydrochloric acid produces 
low yields of LMWC and high yields of monomers [15]. The produced LMWC from the acid depolymerization could be a mixture of different molecular weights, usually with low polydispersity [3235]. In fact, they might have different degrees of deacetylation, which would invariably give rise to different species capable of forming complexes with varying degrees of dissociation $[32,34,40]$.
Interestingly, the degree of deacetylation could be reduced by reacting chitosan solution with acetic anhydride and adding acetyl groups to the polymer chains [41]. Therefore, in this study, low concentration of hydrochloric acid (2M) was used to depolymerize HMWC (500 kDa, 93\% DDA) into LMWC with sufficient yields, reproducible molecular weights and re-acetylation degrees.

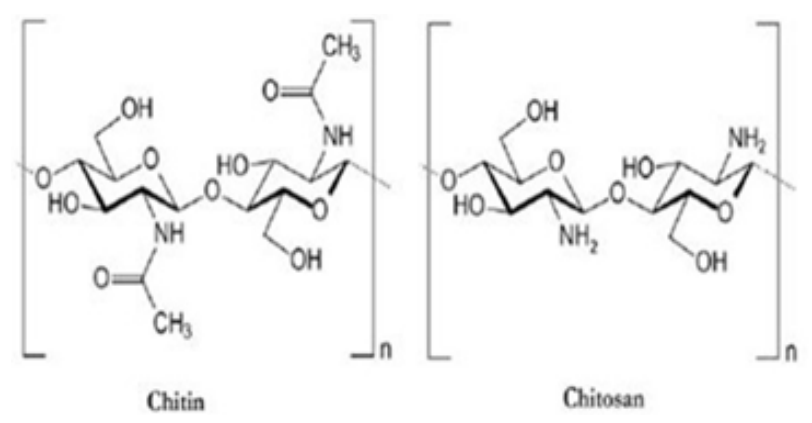

Fig. 1: Chemical structure of chitosan and chitin

\section{MATERIALS AND METHODS}

\section{Materials}

The starting material used in this study is high molecular weight chitosan (500 kDa, 93 \%DDA) which was obtained from Shanghai Company Ltd (China). All other chemicals used were of analytical grade and were used without further purification. Distilled water was use throughout the study for the preparation of solutions and for dilutions where necessary.

\section{Preparation of low molecular weight chitosan (LMWC)}

About $10 \mathrm{~g}$ of high molecular weight chitosan was dissolved in 830 $\mathrm{ml}$ of $0.1 \mathrm{M}$ Hydrochloric acid at ambient temperature for about 30 min, after which concentrated hydrochloric acid $(12.00 \mathrm{M}, 170 \mathrm{ml})$ was added to the solution to obtain $1 \%$ chitosan solution in $2 \mathrm{M}$ Hydrochloric acid. Stirring was continued using a magnetic stirrer (750 rpm) and the solution was kept under reflux during different time intervals. Once the reaction was complete, ethanol was added to the solution in order to facilitate cooling and precipitation of oligo chitosan. The precipitated chitosan was then washed thoroughly in an excess amount of ethanol and centrifuged to eliminate the strong residual acid which often results into browning [42]. The cleaned precipitate was then dried in a freeze dryer to obtain the desired solid-state low molecular weight chitosan (LMWC).

\section{Preparation of LMWC with different degrees of deacetylation}

Low molecular weight chitosan (LMWCs) with Different \%DDAs were prepared from the reaction of the fully deacetylated LMWC obtained from the polymerization reaction with acetic anhydride [16]. Firstly, 1\% LMWC solution was prepared and its $\mathrm{pH}$ was kept close to 6.5 by adding $6 \mathrm{M} \mathrm{NaOH}$ in drops. Then the required amount of acetic anhydride was added to the chitosan solution at ambient temperature under stirring at $500 \mathrm{rpm}$ for $10 \mathrm{~min}$. At the end of the reaction, the chitosan solution was dialyzed through dialysis tubes with 1000 Da molecular weight cut-off against $2 \mathrm{~L}$ of distilled water under mild stirring at ambient temperature over a period of about $24 \mathrm{~h}$. Finally, the dialyzed solution was dried at a temperature of 40 ${ }^{\circ} \mathrm{C}$. Thereafter, samples were stored in amber glass bottles at room temperature until subsequent analysis.

\section{Molecular weight determination of LMWC}

The molecular weight of LMWC was determined through viscosity measurements and applying the Marck-Houwink equation,

$$
[\mathrm{n}]=\mathrm{kM}^{\mathrm{a}} \text {. }
$$

Where $\eta$ and $M$ represents the intrinsic viscosity and molecular weight respectively, whereas $k$ and $a$ are Marck-Houwink constants. The values of $k$ and $a$ are given as $5.8 \times 10^{-4}$ and 0.693 , respectively [43].
Viscosity measurements were conducted using Brookfield rotary viscometer (Brookfield, UK). The standard capacity of the sample holder is $15 \mathrm{ml}$ and the container was placed in a water jacket to keep all measurements at a temperature of $25^{\circ} \mathrm{C}$. Each grade of the prepared LMWC contains $2.5 \mathrm{~g}$ LMWC, dissolved in $50 \mathrm{ml}$ of $0.1 \mathrm{M}$ $\mathrm{HCl}$. Series of dilutions were conducted to obtain solutions of 5, 4, 3, 2 , and $1 \mathrm{wt} \%$. Measurement of solvent and sample viscosities was repeated three times and their average was recorded. The relative viscosity was determined as:

$$
\eta_{\text {rel }}=\frac{\eta}{\eta^{\circ}}-\cdots-------(2)
$$

Where $\eta_{\text {rel }}$ represents the relative viscosity of the polymer, $\eta$ denotes the viscosity of the polymer solution and $\eta^{\circ}$ is the viscosity of the solvent. Then the reduced viscosity (nred) was calculated according to the following expressions:

$$
\begin{aligned}
& \eta_{\text {red }}=\frac{\eta s p}{c}- \\
& \eta_{\text {sp }}=\eta_{\text {rel }}-1
\end{aligned}
$$

Where $\mathrm{C}$ is the concentration of the polymer solution $(\mathrm{w} / \mathrm{v} \%)$.

The relation between intrinsic viscosity and the Molecular weight are represented by the Mark-Houwink equation (1).

The Y-intercept of the plot of reduced viscosity vs. polymer concentration ( $\mathrm{w} / \mathrm{v} \%)$ was used to calculate the intrinsic viscosity. Then from the Mark-Houwink equation, the following can be attained:

$$
\log M=\frac{\log [n]-\operatorname{logk}}{a}-----(5)
$$

Therefore, the molecular weight could be expressed as:

$$
M=10 \frac{\log [\eta]-\operatorname{logk}}{a}-----(6)
$$

\section{Degree of deacetylations of LMWC}

The degree of deacetylation (\%DDA) of the prepared LMWC was obtained through first derivative UV-spectrophotometric procedure (Beckman Coulter spectrophotometer, DU 640i, Brea, CA, USA) adapted from the British Pharmacopeia [44], which is considered to be among the most commonly used methods for determining the \%DDA of chitosan.

Briefly, chitosan sample was dissolved in water to obtain a $50 \mu \mathrm{g} / \mathrm{ml}$ solution. Then, absorbance was taken at the maximum wavelength $(\lambda)$ of $202 \mathrm{~nm}$ as the first derivative of the absorbance curve. The $\mathrm{pH}$ of the solution was also measured. A plot of the first derivative of the absorbance measured at $\lambda_{\max } 202 \mathrm{~nm}$ as a function of the $\mathrm{N}$ acetylglucosamine concentration was used to generate a standard calibration curve. The slope of the curve was obtained by applying 
the least squares linear regression. The concentration of $\mathrm{N}$ acetylglucosamine equivalent to the sample to be examined was then deduced from the standard curve. Then the degree of deacetylation was obtained by applying the following equation:

$$
\% D D A=\frac{(100 \times M 1(C 1-C 2))}{((M 1 \times C 1)-(M 1-M 3) \times C 2)}-------(7)
$$

where; $\mathrm{C} 1$ and $\mathrm{C} 2$ are the concentration $(\mu \mathrm{g} / \mathrm{ml})$ of chitosan, and the concentration of $\mathrm{N}$-acetylglucosamine $(\mu \mathrm{g} / \mathrm{ml})$ in the test solution respectively, $\mathrm{M} 1$ is the relative molecular mass of $\mathrm{N}$ acetylglucosamine unit $(203.2 \mathrm{~g} / \mathrm{mol})$, and $\mathrm{M} 3$ is the relative molecular mass of chitosan sample as calculated from the $\mathrm{pH}$ of the solution, using a pKa of glucosamine equal to 6.8 and by applying Equations 8, 9, and 10 .

$$
\begin{aligned}
& M 3=(f x M 2)+(1-f) x(M 2+36.3)--(8) \\
& f=\frac{p}{1+p} \\
& p=10^{p H-p K a}
\end{aligned}
$$

Where; M2 is the relative molecular weight of glucosamine (197.62 $\mathrm{g} / \mathrm{mol}), f$ is the fraction of ionized species in the aqueous phase, and $\mathrm{p}$ is the partition-coefficient that refers to the concentration ratio of un-ionized species.

\section{${ }^{1}$ HNuclear magnetic resonance method}

The ${ }^{1} \mathrm{H}$-NMR spectra was acquired for all prepared grades of chitosan and chitosan nanofibers, using few milligrams of chitosan. The test samples were dissolved as $30 \mathrm{mg}$ in $1 \mathrm{ml} \mathrm{D}_{2} \mathrm{O}$ and then placed in $5 \mathrm{~mm}$ NMR tubes and analyzed at $70{ }^{\circ} \mathrm{C}$. The ${ }^{1} \mathrm{H}-\mathrm{NMR}$ spectra of chitosan were used to calculate the \%DDA of the different prepared grades as shown in Equation (11) [44].

$$
\% \mathrm{DDA}=\left[1-\left(\frac{0.33 \mathrm{HAc}}{0.167 \mathrm{H} 2-6}\right)\right] \times 100 \%----------(11)
$$

Where, HAc is the height of the acetyl group peak while H2-6 is the sum of the heights of the peaks of C2 to C6.

\section{Fourier transform infrared (FTIR) spectroscopy}

The FTIR spectroscopy analysis of specimens was performed on a Thermo Scientific Nicolet IS50 spectrometer. The samples were analyzed using ATR crystals where each sample was evaluated under mechanical force by pressing the surface of the sample against a diamond window in the range of 4000 to $400 \mathrm{~cm}^{-1}$. The attenuated total reflectance technique was used to carry out the measurement. Before each measurement, the solid demountable cell was dismantled and cleaned with acetone to eliminate possible impurities and contamination. After the samples spectra have been taken, they were further analyzed using Nicolet OMNIC software.

\section{Surface morphology}

The morphological differences of the different samples of LMWCs were observed using Scanning Electron Microscopy (FEI Quanta 200, Hillsboro, OR, USA). The photomicrographs were taken at the same magnifications to facilitate comparison between the different samples.

\section{X-ray diffraction (XRD) analyses}

$\mathrm{X}$-ray diffraction analysis (XRD) is a convenient tool for material analysis. It provides useful information about materials based on their powder diffraction pattern. Herein, XRD was used to investigate the constitutional properties and also to obtain the crystalline nature of chitosan. For this purpose, an X-ray diffractometer (PANalytical X'pert powder Xray Diffractometer, $\mathrm{Cu}$ anode) was used and scanning was conducted over a range of $5^{\circ}-80^{\circ}$ at $1^{\circ}$ deg min $^{-1}$ with sampling step of $0.02^{\circ}$. The data was then analyzed using HighScore Plus software.

\section{Differential scanning calorimetry (DSC)}

The DSC analysis is commonly used for the measurement of thermal transition as well as heat effects on polymers. Generally, this method is used for detecting phase changes such as crystallization, melting, glass transition, and decomposition. In this study, a Perkin Elmer, DSC8000 instrument was used for the DSC analysis. About $2 \mathrm{mg}$ of each powdered sample was placed in closed platinum pans and continuously heated from $30^{\circ} \mathrm{C}$ to $300^{\circ} \mathrm{C}$ at $1{ }^{\circ} \mathrm{C} /$ min to obtain the DSC parameters.

\section{RESULTS AND DISCUSSION}

\section{Effect of the acid hydrolysis on the yield of the produced LMWC}

Different methods can be used to depolymerize HMWC. However, the acid hydrolysis approach which makes use of hydrochloric acid $(\mathrm{HCl})$ is usually preferable, especially at the industrial scale. Herein, different molecular weights of fully deacetylated LMWC were prepared from HMWC (500 kDa, 90\% DDA) using 2M $\mathrm{HCl}$. The depolymerisation reaction was carried out over three different time intervals in order to prepare three different molecular weights of chitosan. The use of $2 \mathrm{M} \mathrm{HCl}$ for the depolymerisation of chitosan could be considered a desirable choice because it presents high yields of LMWC. Table 1 shows the yield of the depolymerized chitosan which was obtained starting with 10 gm of HMWC using 2M $\mathrm{HCl}$ and for different reaction times. As can be seen, the yield of the LMWC decreases as the reaction time increases perhaps due to the formation of soluble products in ethanol such as the monomers and dimmers of glucosamine [15]. Notwithstanding, the yield of this reaction can be considered to be generally high. Notably, acid depolymerization method is considered non-random, practical, and a relatively simple method [45].

However, most of the previously reported studies involve the use of high concentrations of acid which then needs to be removed [22]. It is worthy of note that use of concentrated acid could result in low yields of LMWC, where the yields of pentamer and hexamer could be less than $8 \%$ [46], but with a high monomer yield [22]. Hence, the low concentration of hydrochloric acid used in this study reduces the process aggressiveness and corrosiveness, thereby facilitating extended lifespan for the equipment used in the process of depolymerisation. In addition, the use of dilute hydrochloric acid would eliminate the need for several washing processes to remove excess acid from the produced oligomers. In another vein, the acid concentration could influence the polydispersity of the produced chitosan. Specifically, it has been reported that dilute solution often enhances polydispersity compared to concentrated solutions. This is an indication that dilute solutions will facilitate faster degradation of larger molecular weight chitosan resulting in lower molecular weight distribution [47].

Table 1: Yield of the depolymerisation of HMWC $(n=3)$

\begin{tabular}{llll}
\hline Reaction time [h] & $\mathbf{0 . 5}$ & $\mathbf{1}$ & $\mathbf{2}$ \\
\hline Yield [\%] & $92.1 \pm 0.2$ & $92.3 \pm 0.4$ & $90.1 \pm 0.1$ \\
\hline
\end{tabular}

Data given as mean \pm STDEV

During the acid depolymerisation using hydrochloric acid, the $\mathrm{HCl}$ performs a dual function of breaking glycosidic bonds in chitosan, as well as hydrolysing the $\mathrm{N}$-acetylamides. This would produce lower molecular weight chitosan chains with higher degree of deacetylation, DDA. The mechanisms of the hydrolysis and deacetylation of chitosan by hydrochloric acid are illustrated in fig. 2. As shown in fig. 2(a), hydrolysis of chitosan follows an SN1 mechanism where a carbocation is favourably formed because it is stabilized by resonance with the neighbouring oxygen. This mechanism is typical of acid catalyzed hydrolysis in which the glycosidic oxygen is firstly protonated by the acid catalyst to form an oxonium ion which is a good leaving group. Leaving of the protonated oxygen generates a carbocation that is stabilized by electron donation through resonance from the neighbouring oxygen. 
A water molecule then attacks the carbocation to form a protonated hemiacetal which is then deprotonated by a molecule of water, producing a hemiacetal at the reducing end. In the case of deacetylation as in fig. 2(b), the mechanism is an acid catalyzed acyl nucleophilic substitution leading to amide hydrolysis. The carbonyl oxygen is activated in the acidic media by protonation. Subsequent attack of the carbonyl carbon by a water molecule, as a nucleophile leads to the formation of a tetrahedral intermediate that rearranges, leading to the formation of an acetic acid molecule and an ammonium group in the backbone of chitosan [48].
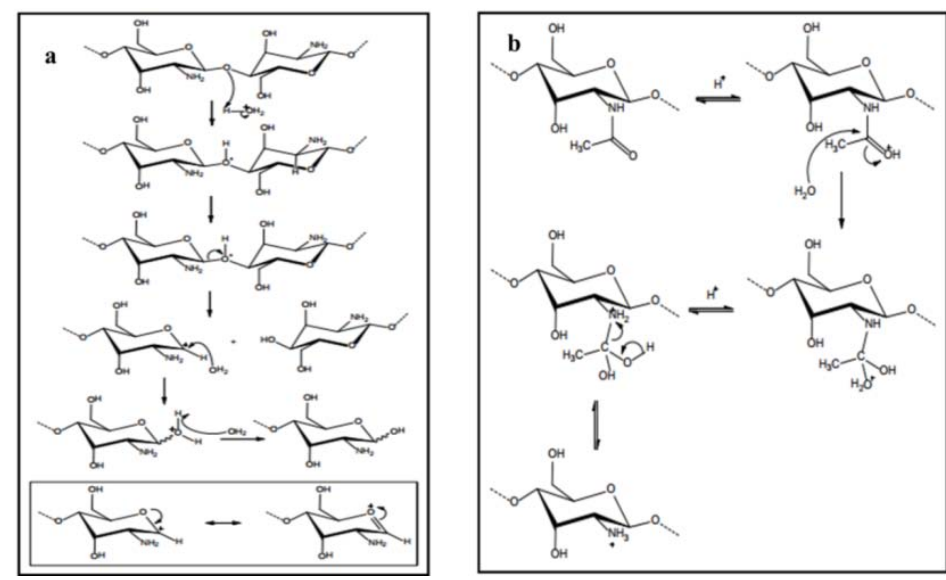

Fig. 2: (a) Hydrolysis mechanism of chitosan polymer during depolymerization, (b) Deacetylation mechanism of chitosan polymer during depolymerisation

Evaluation of the molecular weight of the prepared LMWC using viscosity method

Results indicate that at a constant concentration of $\mathrm{HCl}$, the molecular weight of the resultant chitosan polymers decreases as the reaction time increases. Table 2 shows the viscosity values at the concentrations of $1 \%, 2 \%, 3 \%, 4 \%$ and $5 \%$ of the LMWC prepared at $0.5 \mathrm{~h}, 1 \mathrm{~h}$, and $2 \mathrm{~h}$ depolymerization reaction times. Generally, for all
LMWC the viscosity is proportional to the concentration. For reaction times of $0.5 \mathrm{~h}, 1 \mathrm{~h}$, and $2 \mathrm{~h}$, the maximum concentration prepared was 5 wt $\%$ due to solubility limitations. Also the table shows that there is a direct relationship between the molecular weight of the polymer and its viscosity. The largest viscosity value obtained was for the solutions of LMWC prepared by the reaction performed for $0.5 \mathrm{~h}$, whereas LMWC prepared over a $2 \mathrm{~h}$ reaction period reveals the lowest value which corresponds to lower molecular weight.

Table 2: Viscosity of LMWC preparations with different concentrations (mPa. s) $(n=3)$

\begin{tabular}{|c|c|c|c|}
\hline Concentration (mg/ml) & $0.5 \mathrm{~h}$ & 1h & $2 \mathrm{~h}$ \\
\hline 1 & $1.413 \pm[0.006]$ & $1.410 \pm[0.006]$ & $1.227 \pm[0.006]$ \\
\hline 2 & $2.220 \pm[0.010]$ & $1.775 \pm[0.006]$ & $1.520 \pm[0.006]$ \\
\hline 3 & $3.140 \pm[0.010]$ & $2.775 \pm[0.006]$ & $2.207 \pm[0.006]$ \\
\hline 4 & $4.367 \pm[0.006]$ & $3.420 \pm[0.010]$ & $3.060 \pm[0.010]$ \\
\hline 5 & $6.403 \pm[0.031]$ & $4.485 \pm[0.006]$ & $4.083 \pm[0.006]$ \\
\hline
\end{tabular}

Data given as mean \pm STDEV

Fig. 3 shows the molecular weights of the LMWC as function of the depolymerization reaction time. A decreasing trend in molecular weight of depolymerized chitosan as function of time is obvious in the figure, and the molecular weight-time data could be fitted to a power law function $\left(\mathrm{y}=15.377 \mathrm{x}^{-0.954}\right)$ with $\left(\mathrm{R}^{2}=0.996\right)$. According to the results shown in the fig. it is evident that at a constant concentration of $\mathrm{HCl}$, the molecular weight of the resultant chitosan polymers decreases as the reaction time increases. This observation aligns with what was previously reported in literature $[49,5]$.

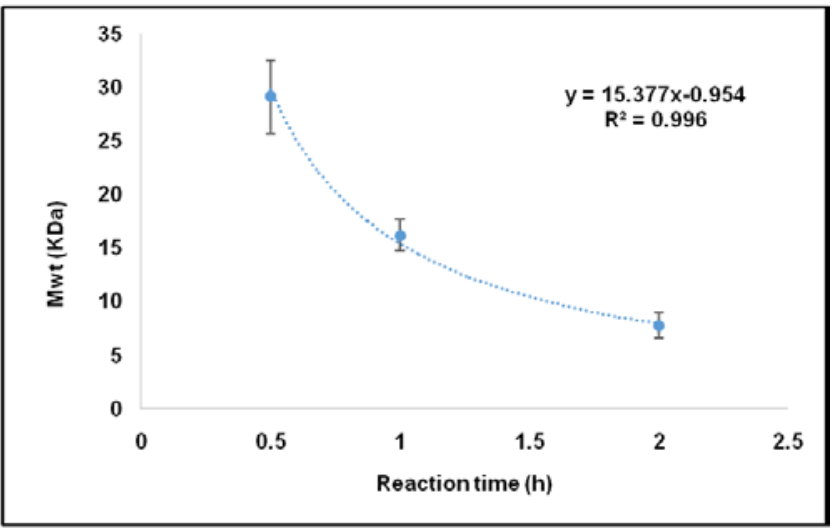

Fig. 3: Molecular weight $(\mathrm{kDa})$ as function of hydrolysis reaction time $(n=3)$ 


\section{Determination of the degree of deacetylation}

The LMWC with different degrees of deacetylation was obtained by reacting fully deacetylated LMWC with acetic anhydride at different molar ratios as summarized in table 3. The UV-visible spectrophotometry was used to determine the \%DDA of each LMWC, after which they were verified using the H-NMR method. On the other hand, first derivative UV method was used to estimate the \%DDA of the LMWC using the calibration curve constructed by defined $\mathrm{N}$-acetyl glucosamine concentrations in which the first derivative of the absorbance function was measured for each sample at $202 \mathrm{~nm}$. The $\mathrm{pH}$ and absorbance values taken for the samples were used to calculate the degree of deacetylations, using Eq (7) and the empirical equations presented in Eq (8), Eq (9), and Eq (10).
It is well known that the H-NMR spectroscopy is more advantageous than other methods for obtaining the degree of deacetylation of chitosan especially for its easy process [9]. In addition, it is more accurate and precise with the possibility to use different combination of peaks [50]. Also, with this method, the amount of chitosan used and its purity are negligible as long as the peaks of impurities do not overlap with the important peaks of chitosan [9].

Results of the H-NMR analysis of LMWC are illustrated in fig. 4. It is evident that there is an increase in the integral of the peak of the three protons of the acetyl group (H-AC) at $2.0 \mathrm{ppm}$ at decreasing $\%$ DDA values. The \%DDA was obtained in accordance with the method proposed by Hirai et al. [11].
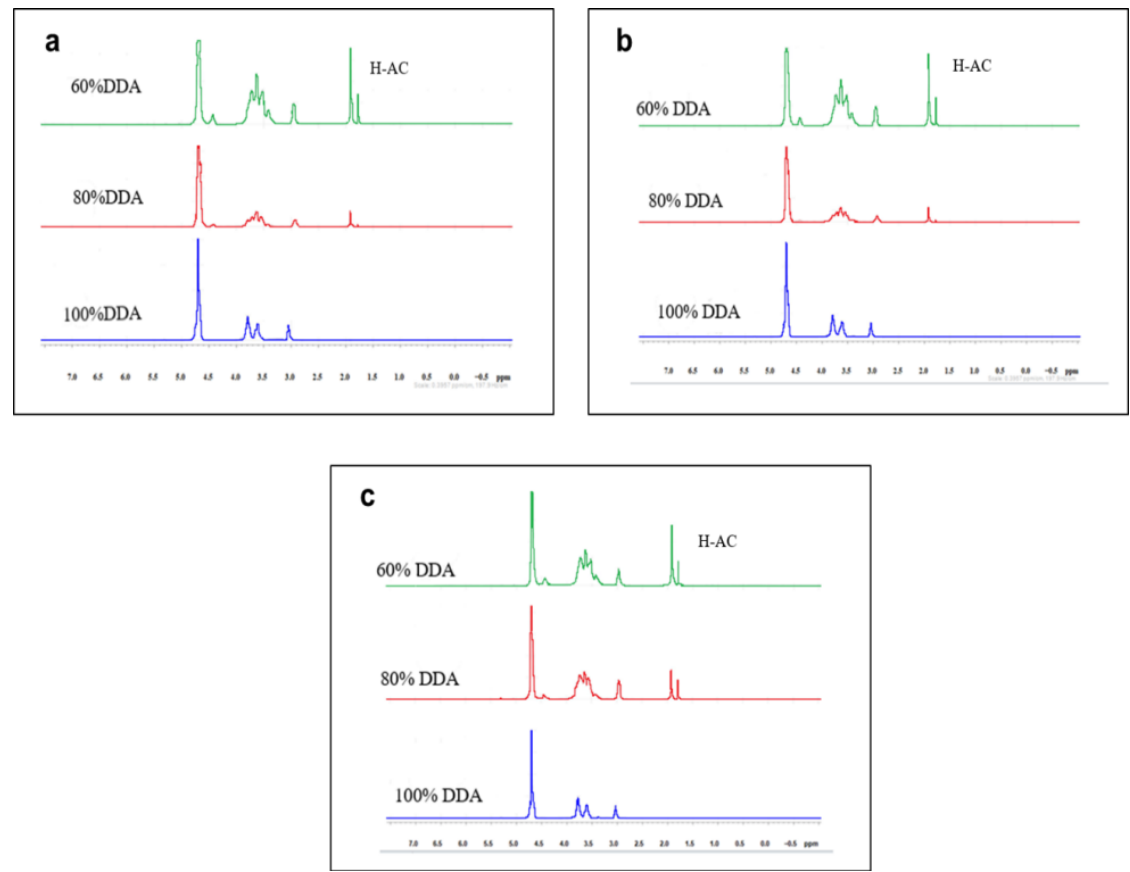

Fig. 4: 1H-NMR spectra for 30KDa LMWC of different \%DDA

From the result presented in table 3 it can be seen that the acid hydrolysis reaction yields fully deacetylated chitosan and this is supported by the H-NMR spectra as evident in the peak of acetyl group (at $2.0 \mathrm{ppm}$ ) which seem to have disappeared. The results in the table also show that the \%DDA values obtained by both methods are comparable. Likewise, it is clear from the results that as the amount of added acetic anhydride increases, more acetyl groups tends to be available on the chitosan molecules such that the calculated \%DDA of chitosan increases according to the chemical reaction shown in Fig.5. Interestingly, these observations conforms to what was previously reported in similar studies $[43,51]$.

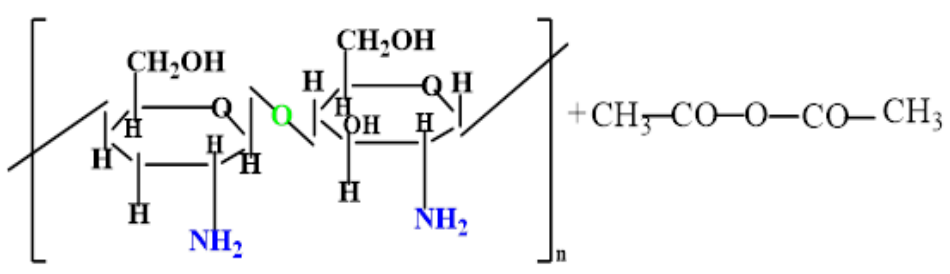

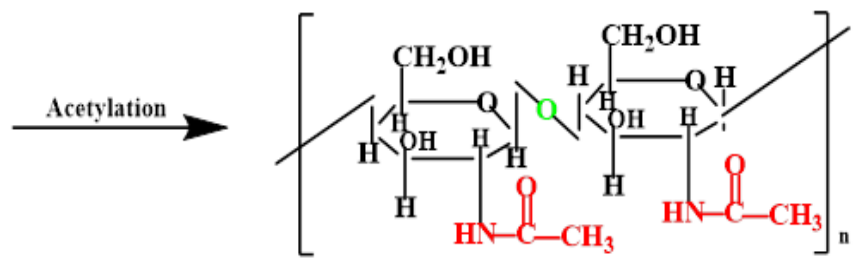

Fig. 5: Chemical reaction between chitosan and acetic anhydride to prepare acetylated chitosan 
Table 3: Molecular weight (Mw) and degree of deacetylation (DDA) determination for LMWC

\begin{tabular}{llll}
\hline Molecular weight & & & \\
\hline Depolymerization time $(\mathrm{h})$ & 0.5 & 15 & \\
LMWC $(\mathrm{kDa})$ & 30 & $(1: 0.15)$ & 7.5 \\
& Degree of deacetylation & 7.51530 & $(1: 1)$ \\
Molar ratio of $\left(\mathrm{Cs}: \mathrm{AC}_{2} \mathrm{O}\right)$ & $(1: 0)$ & 80.379 .980 .1 & 7.51530 \\
LMWC $(\mathrm{kDa})$ & 7.51530 & 80.279 .879 .9 & 59.459 .960 .2 \\
By FDUV method & 98.798 .498 .6 & $80 \%$ & 60.160 .659 .5 \\
By HNMR method & 100100100 & $60 \%$ & \\
\%DDA & $100 \%$ & & \\
\hline
\end{tabular}

\section{Fourier transform infrared (FTIR) spectroscopy}

In the obtained FTIR spectra, the peak position and intensity can appear to be different based on the differences in \%DDA. This could be as a result of different factors such as the polymer source, or its morphology [12]. As illustrated in fig. 6, it can be seen that there is no too much difference in the main skeletal structure of the harvested chitosan and the high molecular weight chitosan, regardless of the depolymerisation time, with respect to the hydrolysis reaction. Therefore, it can be inferred that the acid hydrolysis depolymerisation using $2 \mathrm{M} \mathrm{HCl}$ did not result in significant modification to the structural framework of chitosan. Tables 4, 5, and 6 summarize the major peaks in the FTIR spectra of the different grades of LMWC of $30 \mathrm{kDa}, 15 \mathrm{kDa}$, and $7.5 \mathrm{kDa}$ respectively. Notably, some peaks disappeared due to the hydrolysis reaction, whereas the intensities of others changed due to the acetylation reaction, with slight shifting in the wave number of certain peaks.

Fig.7 shows a comparison between the spectra of different degrees of deacetylation of the different molecular weights prepared. It is obvious that the samples with same \%DDA had the same trend and most of the characteristic peaks are present irrespective of the molecular weight of chitosan. Notably, the wide peak which appeared around $3424 \mathrm{~cm}^{-1}$ is attributed to the stretching of $\mathrm{N}-\mathrm{H}$ groups. Hence, the peaks reveal similar intensities for all the samples, because this band represents the N-H stretching which is available in all chitosan grades (either acetylated or deacetylated). The peak around $1320 \mathrm{~cm}^{-1}$ which is associated with the GlcNAC group can be seen in the spectra of chitosan with $80 \%$ DDA and $60 \%$ DDA whereas this peak is absent in the spectra of totally deacetylated chitosan (100\%DDA). The peak representing the bending of the $\mathrm{NH}_{2}$ group appears at the wavelength in the range of $1624-1629 \mathrm{~cm}^{-1}$. It is worthy of note that the intensity of this peak decreases as the \%DDA of chitosan decreases because less amount of $\mathrm{NH}_{2}$ is available. Also all peaks assigned to the saccharide structures are available in all grades, where the peak around 2890 $\mathrm{cm}^{-1}$ represents the $\mathrm{C}-\mathrm{H}$ stretch, and $1150 \mathrm{~cm}^{-1}$ represents the $\mathrm{C}-\mathrm{N}$ stretch. On the other hand, the peak at $1320 \mathrm{~cm}^{-1}$ is attributed to the stretching of the C-O group [52].

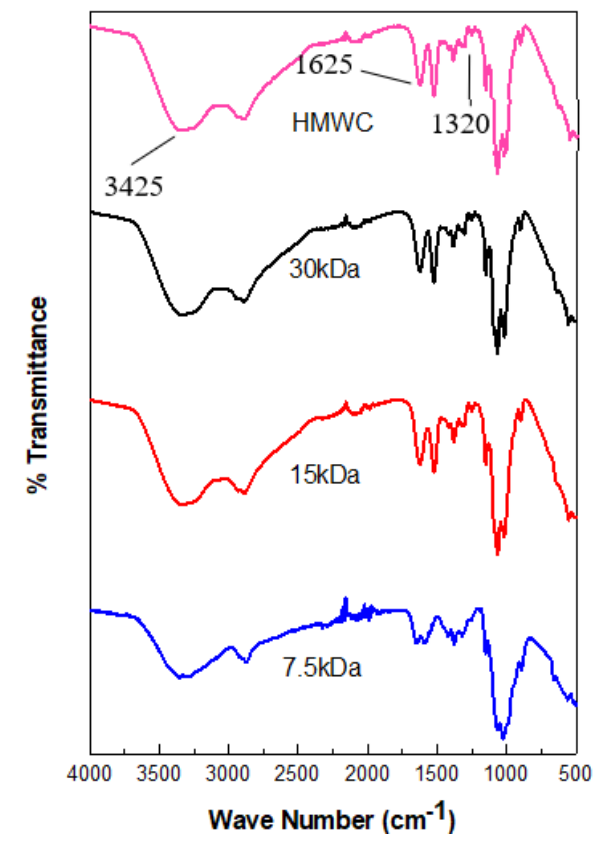

Fig. 6: FT-IR spectra over the frequency range (4000-400) $\mathrm{cm}^{-1}$ for different fully deacetylated LMWCs compared with the HMWC

Table 4: The characteristic FTIR transmittance peaks of the different grades of LMWC $30 \mathrm{kDa}$

\begin{tabular}{lll}
\hline Sample & Wave number $\mathbf{( c m - 1 )}$ & Vibrational mode (s) \\
\hline $30 \mathrm{kDa}, 100 \%$ DDA & 1150.21 & C-N stretching \\
& NA & C-O stretching \\
& 1624.30 & N-H bending \\
& 2888.66 & C-H stretching \\
$30 \mathrm{kDa}, 80 \%$ DDA & 3328.64 & N-H stretching \\
& 1151.05 & C-N stretching \\
& 1319.48 & C-O stretching \\
$30 \mathrm{kDa}, 60 \%$ DDA & 1629.48 & $\mathrm{~N}-\mathrm{H}$ bending \\
& 2884.36 & C-H stretching \\
& 3277.05 & $\mathrm{~N}-\mathrm{H}$ stretching \\
& 1152.0 & C-N stretching \\
& 1316.50 & C-O stretching \\
& 1629.80 & $\mathrm{~N}-\mathrm{H}$ bending \\
& 2887.72 & $\mathrm{C}-\mathrm{H}$ stretching \\
\end{tabular}

\section{Surface morphology}

The variation in the polymer morphology of the different degrees of deacetylation for each molecular weight of chitosan is obvious to the naked eye, and these variations were observed on a Scanning Electron Microscope (SEM). The SEM permits the observation of the materials in both the macro and submicron range and it is also capable of generating three-dimensional images for the analysis of topographic features. In addition, it can provide viable information about the shape of the compound due to the interactions of electron on the sample, which creates a surface map of the sample. The SEM images presented in fig. 8 shows that the fully deacetylated chitosan had rough and 
irregular surface. As the degree of deacetylation decreases, the hydrogen bonds between the polymer chains were decreased. Hence, the $\mathrm{N}$-substituted polymer chains were in good morphological sphericity and aggregated to each other as rosaries and this was the case for the samples of $80 \%$ DDA for the different degrees of deacetylations. Finally, at the lower degree of deacetylation $(60 \%$ DDA) the surface shape of the deacetylated chitosan appeared to be regular, smooth, stretched and looked like a flat surface [16].
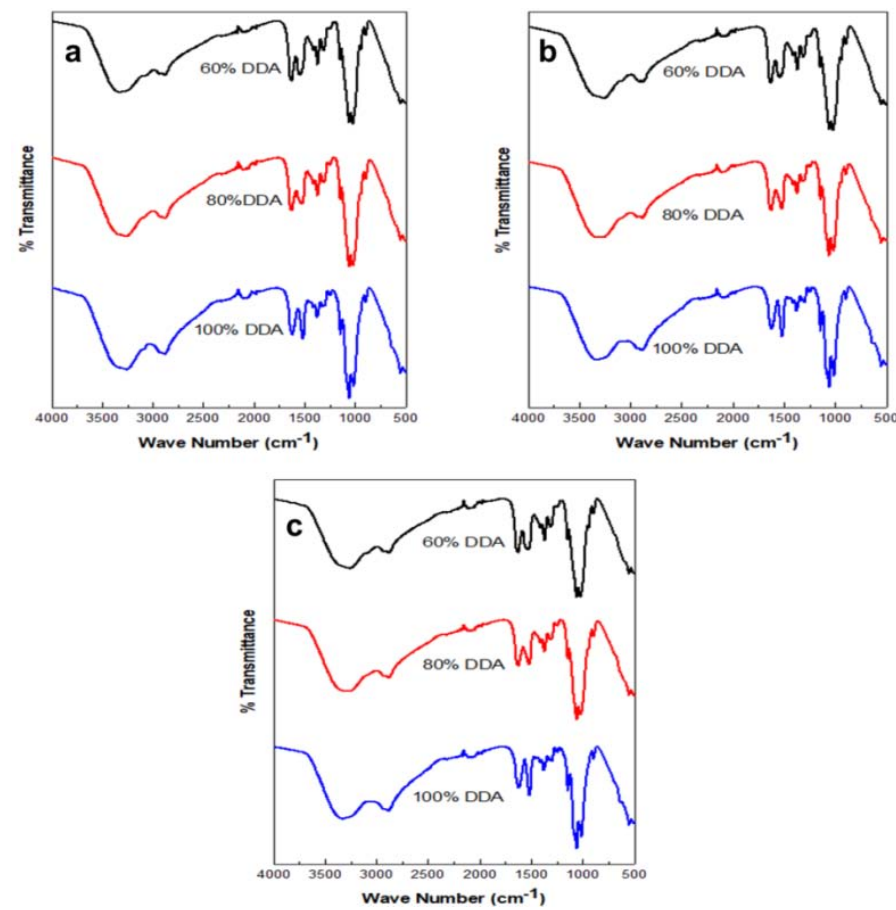

Fig. 7: FT-IR spectra over the frequency range $4000-400 \mathrm{~cm}-1$ of different degrees of deacetylation LMWC(a) $30 \mathrm{kDa}$, (b) $15 \mathrm{kDa}$, (c) $7.5 \mathrm{kDa}$

Table 5: The characteristic FTIR transmittance peaks of the different grades of LMWC 15kDa

\begin{tabular}{lll}
\hline Sample & Wave number (cm-1) & Vibrational mode (s) \\
\hline $15 \mathrm{kDa}, 100 \%$ DDA & 1149.79 & C-N stretching \\
& NA & C-O stretching \\
& 1624.12 & N-H bending \\
& 2889.35 & C-H stretching \\
$15 \mathrm{kDa}, 80 \%$ DDA & 3328.61 & N-H stretching \\
& 1150.62 & C-N stretching \\
& 1321.39 & C-O stretching \\
& 1629.02 & N-H bending \\
$15 \mathrm{kDa}, 60 \%$ DDA & 2888.61 & C-H stretching \\
& 3281.19 & N-H stretching \\
& 1151.57 & C-N stretching \\
& 1315.96 & C-O stretching \\
& 1629.76 & N-H bending \\
& 2917.73 & C-H stretching \\
\hline
\end{tabular}

Table 6: The characteristic FTIR transmittance peaks of the different grades of LMWC 7.5kDa

\begin{tabular}{lll}
\hline Sample & Wave number (cm-1) & Vibrational mode (s) \\
\hline $7.5 \mathrm{kDa}, 100 \%$ DDA & 1149.88 & C-N stretching \\
& NA & C-O stretching \\
& 1624.08 & N-H bending \\
& 2890.17 & C-H stretching \\
$7.5 \mathrm{kDa}, 80 \%$ DDA & 3331.73 & N-H stretching \\
& 1150.69 & C-N stretching \\
& 1320.38 & C-O stretching \\
& 1628.99 & N-H bending \\
$7.5 \mathrm{kDa}, 60 \%$ DDA & 2887.68 & C-H stretching \\
& 3269.75 & N-H stretching \\
& 1151.73 & C-N stretching \\
& 1316.82 & C-O stretching \\
& 1629.63 & N-H bending \\
& 2884.08 & C-H stretching \\
& 3266.24 & N-H stretching \\
\hline
\end{tabular}



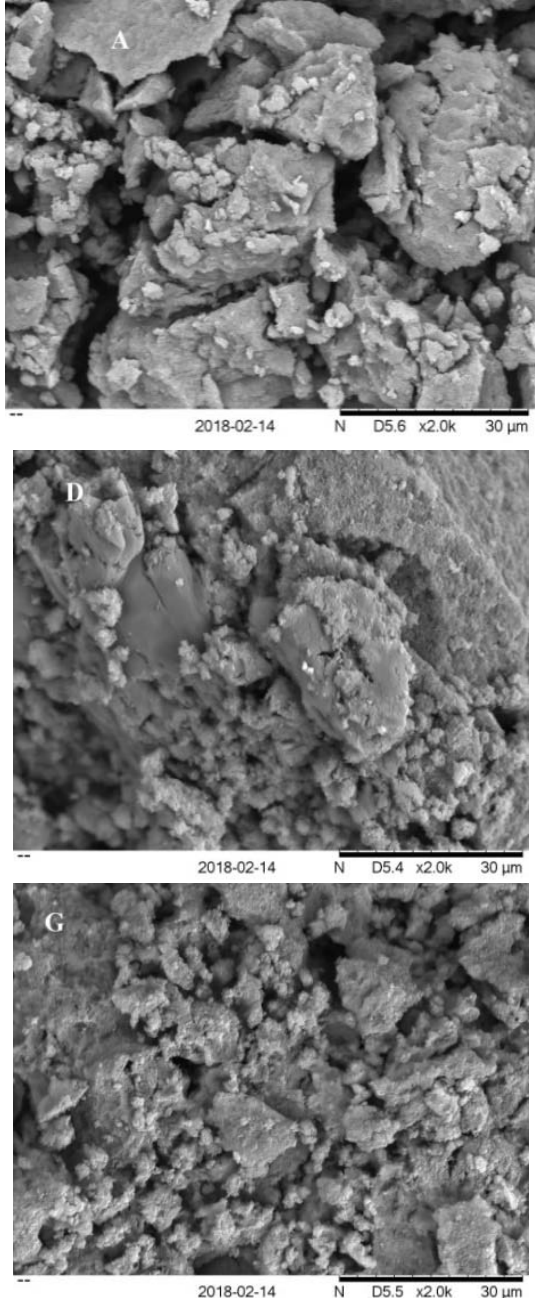
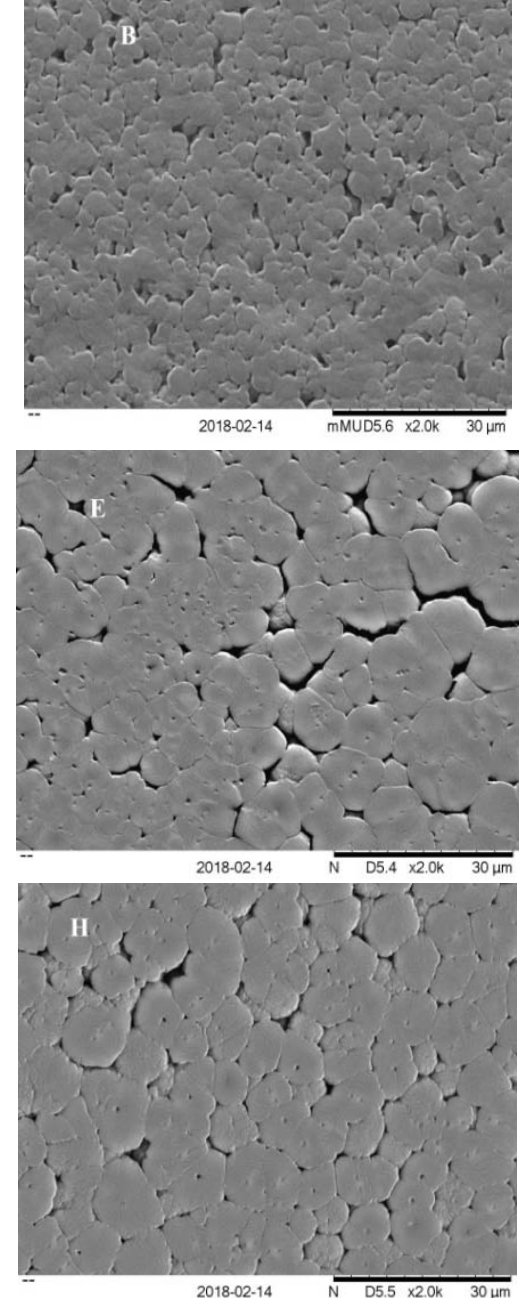
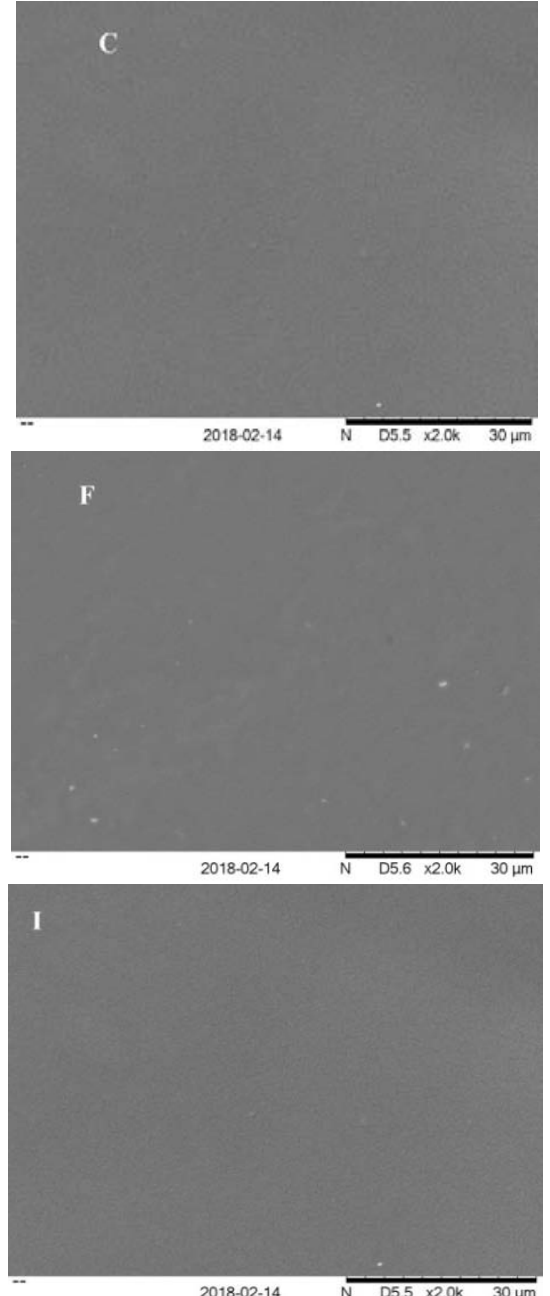

Fig. 8: Scanning electron micrographs (SEM) of chitosan with different molecular weights and degrees of deacetylations with a magnification of 2000X. (A) 30 kDa 100\% DDA, (B) 30 kDa 80\% DDA, (C) 30 kDa 60\% DDA, (D) 15 kDa 100\% DDA, (E) 15 kDa 80\% DDA, (F) 15 kDa 60\% DDA, (G) 7.5 kDa 100\% DDA, (H) 7.5 kDa 80\% DDA, (I) 7.5 kDa 60\% DDA

\section{X-Ray diffraction analysis}

The X-Ray diffraction (XRD) describes the effect of strains which are generated in any crystalline material, which could manifest through shift in diffraction line, or obvious change in lattice planes. Usually, macro stress brings about shift in diffraction line, whereas stress at the micro level would reflect through broadening of diffraction lines.

The XRD patterns of the high molecular weight chitosan and the fully deacetylated LMWC $30 \mathrm{kDa}, 15 \mathrm{kDa}$, and $7.5 \mathrm{kDa}$ are presented in fig. 9. As can be seen, all the samples showed strong sharp peak at the (020) reflection around $10-11^{\circ}$ and broad peaks at $(110)$ reflection around $20-24^{\circ}$, which indicates that all molecular weights of LMWC are partially crystalline as well as the high molecular weight chitosan (HMWC). The intensity of the sharp crystalline peak which appeared at $11^{\circ}$ is almost the same for the $30 \mathrm{kDa}, 15 \mathrm{kDa}$, and 7.5 $\mathrm{kDa}$ chitosan, while the intensity of the broad peak at $24^{\circ}$ increases as the molecular weight of LMWC decreases. The broader peaks present in the XRD profiles of LMWC suggests that it is of less crystallinity compared with the HMWC [53].

Fig. 10 presents the comparative diffractograms of the different degrees of deacetylation of LMWC $30 \mathrm{kDa}, 15 \mathrm{kDa}$, and $7.5 \mathrm{kDa}$. As can be seen from the fig., the fig. exhibit similar trend, where the peaks of the lower \%DDA are broader and of less intensity indicating lower level of crystallinity as the \%DDA decreases [53]. It is obvious in fig. 10 that the maximum peak intensity at $(020)$ reflection decreased with the decrease of \%DDA, and moved to a higher angle. Likewise, the second maximum peak (110) reflection also decreased with the decrease of \%DDA. Notwithstanding, the peak appeared at about the same position. In the case of the chitosan with lower degree of deacetylation $(60 \%)$, for all studied molecular weights, the peak at (020) reflection disappeared indicating amorphousness of the sample, which could be due to the higher amount of acetic acid reacted with the fully deacetylated chitosan to produce the grades of $60 \%$ DDA. The higher acetic acid might have produced chitosan with less anhydrous crystals, such that the produced chitosan will be of less crystallinity as reported elsewhere $[53,54]$. The sharp peaks around $18^{\circ}$ could be due to the presence of impurities in the tested samples as this peak do not represent any of the notable peaks of chitosan [15].

The relative crystallinity of the studied samples was calculated and the results are presented in table 8. It is evident from the results that LMWC of $100 \%$ and $80 \%$ DDA are semi crystalline, showing two diffraction peaks at $2 \theta$ around $11^{\circ}$ and $24^{\circ}$, which is associated with semi crystalline chitosan. The semi crystallinity of chitosan was also reported by Islam et al. in 2011 while studying its XRD pattern. They reported that the broad diffraction peaks at $2 \theta$ around $10^{\circ}$ and $21^{\circ}$ represents the semi crystalline chitosan [55]. Similarly, Yen, Yang and Mau in 2009 stated that the two characteristic crystalline peaks of chitosan are at $9-10^{\circ}$ and $19-20^{\circ}$, and that they possess comparable crystallinity [56]. 
Table 7: XRD parameters of the different grades of LMWC's

\begin{tabular}{lll}
\hline Sample & $\left.\mathbf{2 \theta} \mathbf{(}^{\circ}\right)$ & Relative crystallinity (\%) \\
\hline $30 \mathrm{kDa}, 100 \%$ DDA & $11.33,25.17$ & 50.25 \\
$30 \mathrm{kDa}, 80 \%$ DDA & $11.49,23.93$ & 65.91 \\
$15 \mathrm{kDa}, 100 \%$ DDA & $11.45,22.77$ & 44.6 \\
$15 \mathrm{kDa}, 80 \%$ DDA & $11.56,24.87$ & 67.79 \\
$7.5 \mathrm{kDa}, 100 \%$ DDA & $11.38,24.03$ & 42.66 \\
$7.5 \mathrm{kDa}, 80 \%$ DDA & $11.56,23.74$ & 64.47 \\
\hline
\end{tabular}

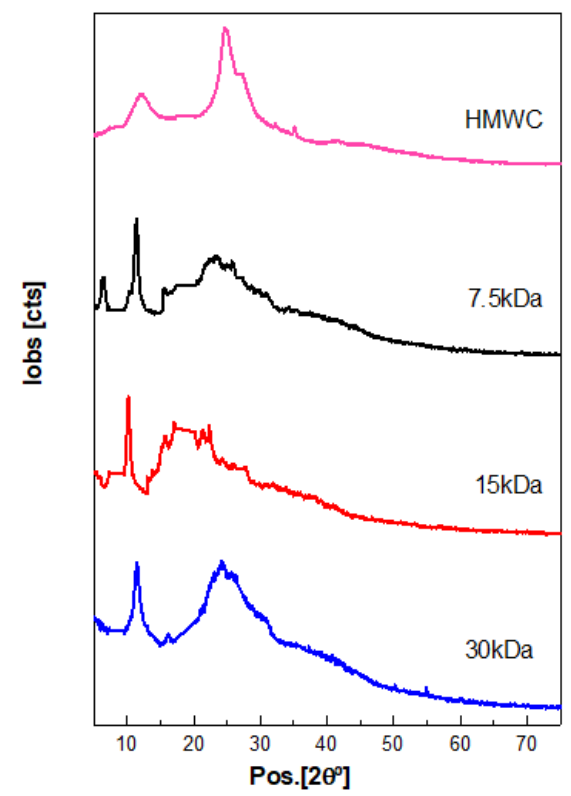

Fig. 9: XRD spectra of different molecular weight of fully deacetylated chitosans (LMWCs) compared with the high molecular weight chitosan (HMWC)
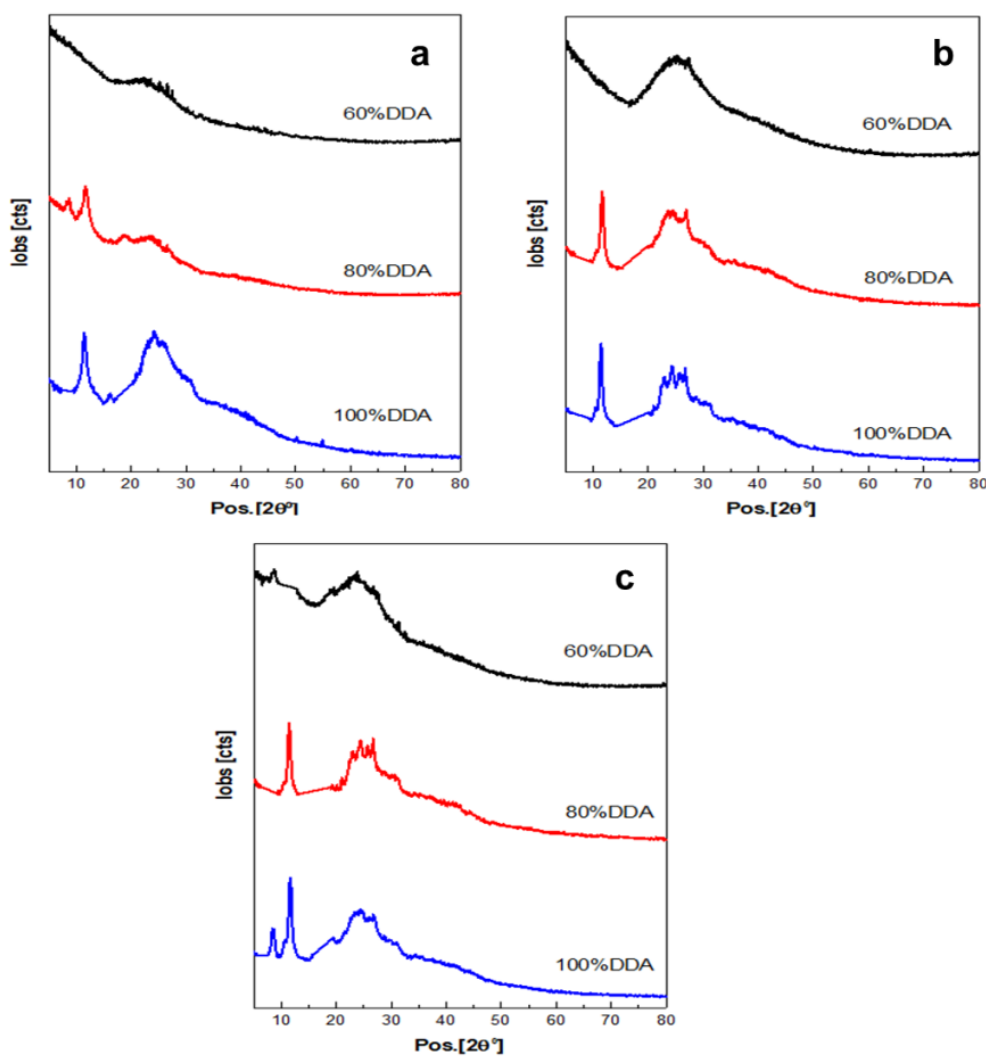

Fig. 10: XRD spectra of different degrees of deacetylation of LMWC (a) $30 \mathrm{KDa}$, (b) $15 \mathrm{KDa}$, and (c) $7.5 \mathrm{KDa}$ 


\section{Differential scanning calorimetry (DSC)}

The DSC thermograms of the different grades of LMWC are illustrated in fig. 11. Generally, in all the DSC curves, three distinct successive transitions can be seen. The first endothermic peak represents the glass transition temperature $\left(\mathrm{T}_{\mathrm{g}}\right)$, the second peak is an exothermic transition representing the crystallization temperature $\left(\mathrm{T}_{\mathrm{c}}\right)$, and the third endothermic peak represents the melt transition $\left(\mathrm{T}_{\mathrm{m}}\right)$.

As presented in fig. 11, the $T g_{\mathrm{g}}$ of all the tested LMWC samples is in the range of $148-177^{\circ} \mathrm{C}$. As discussed earlier, chitosan is considered as partially crystalline. Notwithstanding, the change of the heat capacity might be small at the $\mathrm{Tg}$ due to the rigid 2-amino-2-deoxy-Dglucopyranose (Glucosamine residues) present in chitosan molecules. This is believed to account for the small base line step in the DSC curve as previously reported [53]. The values of $\mathrm{Tg}$ for all LMWC samples as summarized in table 8 indicates that as the \%DDA increases, the $\mathrm{Tg}$ decreases. This could be explained by comparing the molecular structures of chitosan with $60 \%$ DDA, $80 \%$ DDA, and of $100 \%$ DDA. Actually as the \%DDA decreases more acetyl groups will be available in the chains of chitosan making the chains more rigid. So chitosan with higher \%DDA will have fewer acetyl groups compared with the lower \%DDA. This will make it more flexible in the amorphous regions leading to lower $\mathrm{Tg}$, as previously reported [57].

The $T c$ of the samples as presented in table 8 shows that as molecular weight increases, $T c$ of the fully deacetylated LMWC shifts to higher temperature region. This is an indication of slower crystallization which can be attributed to the increase in the molecular weight of chitosan [57] (Sakurai et al., 2000). This observation aligns with the XRD results as discussed above. On the other hand, for the same molecular weight, by comparing $T c$ for the different \%DDA, it can be seen that there is a slight change in $T c$, but with similar trend as the fully acetylated chitosan. This is an indication of slower crystallization which may be accrued to the presence of acetyl groups [15].

The Tm was difficult to be estimated as shown in the fig. 11 . This could be due to the fact that chitosan is not an individual compound but it is a polymer of variable length and molecular weight, so it is considered a mixture of compounds, and thus different samples have different compositions, so chitosan cannot have a unique melting point [15]. The intra-and inter-molecular hydrogen bonds which generate a stable and rigid semi-crystalline structure makes chitosan also degradable before melting because of the high melt viscosity, which is a characteristic of polysaccharides with several hydrogen bonds.
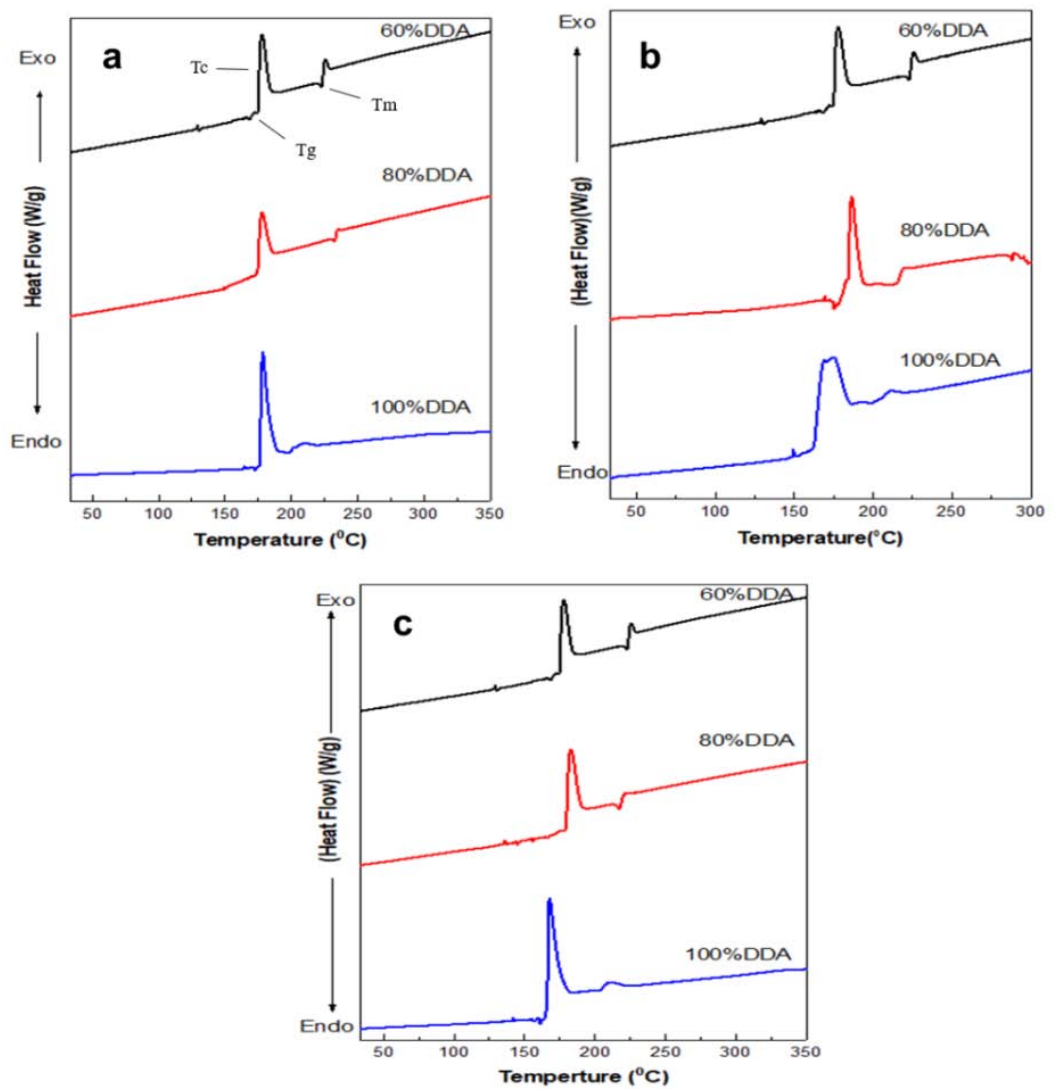

Fig. 11: DSC spectra of different degrees of deacetylation of (a) LMWC $30 \mathrm{kDa}$, (b) LMWC $15 \mathrm{kDa}$, (c) LMWC 7.5 kDa

Table 8: Summary of $T g$, and $T c$, of the different grades LMWC

\begin{tabular}{|c|c|c|}
\hline Sample ID & $\operatorname{Tg}\left({ }^{\circ} \mathrm{C}\right)$ & Tc $\left({ }^{\circ} \mathrm{C}\right)$ \\
\hline $30 \mathrm{kDa}, 100 \% \mathrm{DDA}$ & 155.77 & 180.3 \\
\hline $30 \mathrm{kDa}, 80 \% \mathrm{DDA}$ & 163.15 & 178.8 \\
\hline $30 \mathrm{kDa}, 60 \% \mathrm{DDA}$ & 173.20 & 178.4 \\
\hline $15 \mathrm{kDa}, 100 \% \mathrm{DDA}$ & 156.54 & 172.4 \\
\hline $15 \mathrm{kDa}, 80 \% \mathrm{DDA}$ & 167.45 & 187.60 \\
\hline 15kDa, 60\%DDA & 173.20 & 178.11 \\
\hline $7.5 \mathrm{kDa}, 100 \% \mathrm{DDA}$ & 148.80 & 170.20 \\
\hline 7.5kDa, 80\%DDA & 157.99 & 183.60 \\
\hline $7.5 \mathrm{kDa}, 60 \% \mathrm{DDA}$ & 173.22 & 177.90 \\
\hline
\end{tabular}




\section{CONCLUSION}

In this study, acid hydrolysis method using dilute hydrochloric acid (2M) was used to prepare different grades of LMWC. The hydrolysis reaction produced totally deacetylated LMWC. Specifically, $30 \mathrm{kDa}$, $15 \mathrm{kDa}$, and $7.5 \mathrm{kDa}$ were produced from the hydrolysis reaction carried out for $0.5 \mathrm{~h}, 1 \mathrm{~h}$, and $2 \mathrm{~h}$ respectively. Reaction of the produced LMWC with Acetic anhydride in the molar ratios 1:0.15 and $1: 1$ resulted in \%DDA of $80 \%$ and $60 \%$ respectively. The FTIR, XRD, and DSC of all produced grades of the LMWC were investigated as part of the structure and thermal characterization. The FTIR results revealed that there is no too much difference in the main skeletal structure of the LMWC and HMWC. On the other hand, the XRD and DSC results showed that the LMWC of different molecular weights and degrees of deacetylations are of semi crystaline structure, similar to the HMWC. The acid hydrolysis method could be considered to possess good potential to produce the different grades of LMWC with high yields and good specifications and quality. The different physicochemical characteristics of the produced LMWC's could affect the role of chitosan in different applications, especially in designing drug delivery systems.

\section{ACKNOWLEDGMENT}

The authors would like to thank the Ministry of Higher Education, Malaysia for providing the fund for this project through FGRS (FGRS/1/2019/TK05/UMP/02/13) and Universiti Malaysia Pahang through short term grant (RDU180354).

\section{FUNDING}

Nil

\section{AUTHORS CONTRIBUTIONS}

All the authors have contributed equally.

\section{CONFLICT OF INTERESTS}

The authors declare no conflict of interest.

\section{REFERENCES}

1. Patel DP, Singh S. Chitosan: a multifacet polymer. Int J Curr Pharm Res 2015;7:21-8

2. Sabnis S, Block LH. Chitosan as an enabling excipient for drug delivery systems: I. Molecular modifications. Int J Biol Macromol 2000;3:181-6.

3. Morsi N, Ghorab D, Refai H, Teba H. Preparation and evaluation of Alginate/Chitosan nanodispersions for ocular delivery. Int J Pharm Pharm Sci 2015;7:234-40.

4. Berth G, Dautzenberg H. The degree of acetylation of chitosans and its effect on the chain conformation in aqueous solution. Carbohydr Polym 2002;1:39-51.

5. Yadav A, Bhise S. Chitosan: a potential biomaterial effective against typhoid. Curr Sci 2004;9:1176-8.

6. Fahrurroji A, Thendriani D, Riza H. Hesperidin hydrogel formulation using pectin-chitosan polymer combination. Int J Pharm Pharm Sci 2017;9:98-104.

7. John L, Kumar A. Comparison of amlodipine transdermal patches using hydroxypropylmethylcellulose and chitosan. Asian J Pharm Clin Res 2014; 7:86-90.

8. No HK, Meyers SP, Prinyawiwatkul W, Xu Z. Applications of chitosan for improvement of quality and shelf life of foods: a review. J Food Sci 2007;72:87-100.

9. Zohuriaan Mehr MJ. Advances in chitin and chitosan modification through graft copolymerization: a comprehensive review. Iran Polym J 2005;3:235-65.

10. Kumar MNR. A review of chitin and chitosan applications. React Funct Polym 2000;1:1-27.

11. Shahidi F, Arachchi JKV, Jeon YJ. Food applications of chitin and chitosans. Trends Food Sci Technol 1999;2:37-51.

12. Jin Li, Yumin Du, Jianhong Yang, Tao Feng, Aihua Li, Ping Chen. Preparation and characterisation of low molecular weight chitosan and chito-oligomers by a commercial enzyme. Polym Degrad Stab 2005;3:441-8.

13. Prabaharan M, Mano J. Chitosan-based particles as controlled drug delivery systems. Drug Delivery 2004;1:41-57.
14. Jeon YJ, Shahidi F, Kim SK. Preparation of chitin and chitosan oligomers and their applications in physiological functional foods. Food Rev Int 2000;2:159-76.

15. Qandil AM, Obaidat AA, Ali MAM, Al-Taani BM, Tashtoush BM, Al-Jbour ND, et al. Investigation of the interactions in complexes of low molecular weight chitosan with ibuprofen. J Solution Chem 2009;6:695-712.

16. Qinna NA, Karwi QG, Al-Jbour N, Al-Remawi MA, Alhussainy TM, Al-So'ud KA, et al. Influence of molecular weight and degree of deacetylation of low molecular weight chitosan on the bioactivity of oral insulin preparations. Mar Drugs 2015;13:1710-25.

17. Kumar MN, Muzzarelli RA, Muzzarelli C, Sashiwa H, Domb AJ. Chitosan chemistry and pharmaceutical perspectives. Chem Rev 2004;104:6017-84

18. Rinaudo M. Chitin and chitosan: properties and applications. Prog Polym Sci 2006;7:603-32.

19. Aam BB, Heggset EB, Norberg AL, Sørlie M, Varum KM, Eijsink VG. Production of chitooligosaccharides and their potential applications in medicine. Mar Drugs 2010;8:1482-517.

20. Kumar AV, Tharanathan R. A comparative study on depolymerization of chitosan by proteolytic enzymes. Carbohydr Polym 2004;3:275-83.

21. Giustina A, Ventura P. Weight-reducing regimens in obese subjects: effects of a new dietary fiber integrator. Acta Toxicol Ther 1995;16:199-214.

22. Kim SK, Rajapakse N. Enzymatic production and biological activities of chitosan oligosaccharides (COS): a review. Carbohydr Polym 2005;4:357-68.

23. Lee SH, Suh J, Kim HS, Lee JD, Song J, Lee SK. MR evaluation of radiation synovectomy of the knee by means of intra-articular injection of holmium-166-chitosan complex in patients with rheumatoid arthritis: results at 4-month follow-up. Korean J Radiol 2003;3:170-8.

24. Macchi G. A new approach to the treatment of obesity: chitosan's effects on body weight reduction and plasma cholesterol's levels. Acta Toxicol Ther 1996;17:303-22.

25. Nishimura K, Nishimura S, Nishi N, Saiki I, Tokura S, Azuma I. Immunological activity of chitin and its derivatives. Vaccine 1984;2:93-9.

26. Tokoro A, Kobayashi M, Tatewaki N, Suzuki K, Okawa Y, Mikami T, et al. Protective effect of $\mathrm{N}$-acetyl chitohexaose on listeria monocytogenes infection in mice. Microbiol Immunol 1989;33:357-67.

27. De Britto D, Campana Filho SP. Kinetics of the thermal degradation of chitosan. Thermochim Acta 2007;1:73-82.

28. Kasaai MR. Calculation of mark-houwink-sakurada (MHS) equation viscometric constants for chitosan in any solventtemperature system using experimental reported viscometric constants data. Carbohydr Polym 2007;3:477-88.

29. Kumar ABV, Varadaraj MC, Gowda LR, Tharanathan RN. Characterization of chito-oligosaccharides prepared by chitosanolysis with the aid of papain and pronase, and their bactericidal action against Bacillus cereus and Escherichia coli. Biochem J 2005;391 Pt 2:167-75.

30. Kurita K. Chitin and chitosan: functional biopolymers from marine crustaceans. Mar Biotechnol (NY) 2006;8:203-26.

31. Chang KLB, Tai MC, Cheng FH. Kinetics and products of the degradation of chitosan by hydrogen peroxide. J Agric Food Chem 2001;10:4845-51.

32. Chen RH, Chang JR, Shyur JS. Effects of ultrasonic conditions and storage in acidic solutions on changes in molecular weight and polydispersity of treated chitosan. Carbohydr Res 1997;4:287-94.

33. Tang E, Huang M, Lim L. Ultrasonication of chitosan and chitosan nanoparticles. Int J Pharm 2003;1:103-14.

34. Einbu A, Grasdalen H, Varum KM. Kinetics of hydrolysis of chitin/chitosan oligomers in concentrated hydrochloric acid. Carbohydr Res 2007;8:1055-62.

35. Osorio Madrazo A, David L, Trombotto S, Lucas JM, Peniche Covas C, Domard A. Highly crystalline chitosan produced by multi-steps acid hydrolysis in the solid-state. Carbohydr Polym 2011;4:1730-9.

36. Jeon YJ, Kim SK. Production of chitooligosaccharides using an ultrafiltration membrane reactor and their antibacterial activity. Carbohydr Polym 2000;2:133-41. 
37. Kuroiwa T, Ichikawa S, Hiruta O, Sato S, Mukataka S. Factors affecting the composition of oligosaccharides produced in chitosan hydrolysis using immobilized chitosanases. Biotechnol Progress 2002;5:969-74.

38. Anderson DR, Frisque AJ. Process for rapidly dissolving watersoluble polymers: US Patent RE28,474; 1975.

39. Lee MY, Var F, Shin-ya Y, Kajiuchi T, Yang JW. Optimum conditions for the precipitation of chitosan oligomers with DP 5-7 in concentrated hydrochloric acid at low temperature. Process Biochem 1999;5:493-500.

40. Kurita K. Controlled functionalization of the polysaccharide chitin. Prog Polym Sci 2001;9:1921-71.

41. Roberts G. Chitin chemistry the macmillan press. Basingstoke, Great Britain; 1992.

42. Knill C, Kennedy J, Mistry J, Miraftab M, Smart G, Groocock M, et al. Acid hydrolysis of commercial chitosan. J Chem Technol Biotechnol 2005;80:1291.

43. Elsayed A, Remawi MA, Qinna N, Farouk A, Badwan A. Formulation and characterization of an oily-based system for oral delivery of insulin. Eur J Pharm Biopharm 2009;2:269-79.

44. Pharmacopoeia B. Specific monograph: British Pharmacopoeia Commission: London; 2015.

45. Cabrera JC, Van Cutsem P. Preparation of chitooligosaccharides with degree of polymerization higher than 6 by acid or enzymatic degradation of chitosan Biochem. Eng J 2005;25:165-72.

46. Lee MY, Var F, Shin-ya Y, Kajiuchi T, Yang JW. Optimum conditions for the precipitation of chitosan oligomers with DP 5-7 in concentrated hydrochloric acid at low temperature. Process Biochem 1999;34:493-500.

47. Haider S, Park SY. Preparation of the electrospun chitosan nanofibers and their applications to the adsorption of $\mathrm{Cu}$ (II) and $\mathrm{Pb}(\mathrm{II})$ ions from an aqueous solution. J Membrane Sci 2009;328:90-6.
48. Varum K, Ottøy M, Smidsrød O. Acid hydrolysis of chitosans. Carbohydr Polym 2001;46:89-98.

49. No H, Meyers SP, Prinyawiwatkul W, Xu Z. Applications of chitosan for improvement of quality and shelf life of foods: a review. J Food Sci 2007;72:87-100.

50. Kumar MNR. A review of chitin and chitosan applications. React Funct Polym 2000;46:1-27.

51. Sweidan K, Jaber A, Al-Jbour N, Obaidat R, Al-Remawi M, Badwan A. Further investigation on the degree of deacetylation of chitosan determined by potentiometric titration. J Excipients Food Chem 2011;2:16-25.

52. Athamneh N, Tashtoush B, Qandil A, Al-Tanni B, Obaidat A, AlJbour $\mathrm{N}$, et al. A new controlled-release liquid delivery system based on diclofenac potassium and low molecular weight chitosan complex solubilized in polysorbates. Drug Dev Ind Pharm 2010;39:1217-122.

53. Kumirska J, Czerwicka M, Kaczynski Z, Bychowska A, Brzozowski K, Thoming J, et al. Application of spectroscopic methods for structural analysis of chitin and chitosan. Mar Drugs 2010;8:1567-636.

54. Zhang Y, Xue C, Xue Y, Gao R, Zhang X. Determination of the degree of deacetylation of chitin and chitosan by X-ray powder diffraction. Carbohydr Res 2005;340:1914-7.

55. Islam MM, Masum SM, Rahman MM, Molla MAI, Shaikh A, Roy S. Preparation of chitosan from shrimp shell and investigation of its properties. Int J Basic Appl Sci 2011;11:77-80.

56. Yen MT, Yang JH, Mau JL. Physicochemical characterization of chitin and chitosan from crab shells. Carbohyd Polym 2009;75:15-21.

57. Sakurai K, Maegawa T, Takahashi T. Glass transition temperature of chitosan and miscibility of chitosan/poly $(\mathrm{N}$ vinyl pyrrolidone) blends. Polymer 2000;41:7051-6. 